\title{
Spectral Crop Coefficient Approach for Estimating Daily Crop Water Use
}

\author{
Nithya Rajan ${ }^{*}$, Stephan J. Maas ${ }^{2}$ \\ ${ }^{1}$ Texas A \& M AgriLife Research and Extension Center, Vernon, Texas, USA \\ ${ }^{2}$ Texas Tech University and Texas A \& M AgriLife Research Center, Lubbock, Texas, USA \\ Email: nrajan@ag.tamu.edu
}

Received 26 July 2014; revised 20 August 2014; accepted 16 September 2014

Copyright (C) 2014 by authors and Scientific Research Publishing Inc.

This work is licensed under the Creative Commons Attribution International License (CC BY). http://creativecommons.org/licenses/by/4.0/

(c) (i) Open Access

\begin{abstract}
While the amount of water used by a crop can be measured using lysimeters or eddy covariance systems, it is more common to estimate this quantity based on weather data and crop-related factors. Among these approaches, the standard crop coefficient method has gained widespread use. A limitation of the standard crop coefficient approach is that it applies to "standard conditions" that are invariant from field to field. In this article, we describe a method for estimating daily crop water use (CWU) that is specific to individual fields. This method, the "spectral crop coefficient" approach, utilizes a crop coefficient numerically equivalent to the crop ground cover observed in a field using remote sensing. This "spectral crop coefficient" $K_{s p}$ is multiplied by potential evapotranspiration determined from standard weather observations to estimate CWU. We present results from a study involving three farmers' fields in the Texas High Plains in which CWU estimated using the $K_{s p}$ approach is compared to observed values obtained from eddy covariance measurements. Statistical analysis of the results suggests that the $K_{s p}$ approach can produce reasonably accurate estimates of daily CWU under a variety of irrigation strategies from fully irrigated to dryland. These results suggest that the $K_{\text {sp }}$ approach could be effectively used in applications such as operational irrigation scheduling, where its field-specific nature could minimize over-irrigation and support water conservation.
\end{abstract}

\section{Keywords}

Crop Coefficient, Evapotranspiration, Water Use, Ground Cover, Remote Sensing

\section{Introduction}

Information on the amount of water used by a growing crop is useful in a number of applications. These include *Corresponding author. 
irrigation scheduling, selecting water-efficient crops and cropping systems, and assessing the impact of crops on regional water resources. Crop water use can be measured in the field using devices such as weighing lysimeters and eddy covariance systems. Weighing lysimeters are immovable and thus can only collect data on water use from the fields in which they have been installed. Eddy covariance systems can be moved from field to field to make measurements, but their substantial cost often limits the number that is deployed in a project. While accurate, these devices are not appropriate for collecting water use data from a large number of fields within a region.

An alternative approach to measuring crop water use is to estimate it. Equations that take into account the energy balance and aerodynamic characteristics of the plant canopy, such as the Penman-Monteith Equation, have been used to estimate the evapotranspiration of crops and other vegetation [1]. A simplification of this approach commonly used in irrigation scheduling involves splitting the computations into two steps. In the first step, potential evapotranspiration (PET) for a hypothetical reference crop is calculated from weather data using a modified form of the Penman-Monteith Equation. In the second step, this "reference evapotranspiration" (ET $\left.{ }_{0}\right)$ is multiplied by an empirically determined factor (the "crop coefficient" $\mathrm{K}_{\mathrm{c}}$ ) to produce a value of "crop evapotranspiration" $\left(\mathrm{ET}_{\mathrm{c}}\right)$ presumably appropriate for the crop under investigation. This "crop coefficient approach" has been standardized for application to a wide range of crops around the world [2].

Standard crop coefficients are designed to estimate $\mathrm{ET}_{\mathrm{c}}$ under "standard conditions" which represent "the upper envelope of crop ET where no limitations are placed on crop growth or ET due to water shortage, crop density, or disease, weed, insect, or salinity pressures” [2]. Thus, the standard crop coefficient approach can indicate how much water a crop would be using if it were growing under "standard” (non-limited) conditions. It can't tell you how much water the crop in a particular field is actually using, particularly if the growth of the crop is limited by management practices such as deficit irrigation. In such situations, the standard crop coefficient approach will likely result in over-estimation of the amount of water used by the crop.

Standard crop coefficients are often determined from field studies involving measurements of ET made using weighing lysimeters. They are determined as the ratio of measured $\mathrm{ET}$ to calculated $\mathrm{ET}_{0}$. Thus, crop coefficients are not physical quantities and cannot be directly measured in the field. This feature makes it difficult to adjust the values of crop coefficients to account for non-standard growing conditions. A few attempts have been made to use remote sensing observations to evaluate or adjust the values of crop coefficients [3]-[9]. In these cases, empirical relationships were developed between $\mathrm{K}_{\mathrm{c}}$ and remote sensing data, usually in the form of a vegetation index like NDVI. Such relationships are likely to be site-specific.

Over the past decade, we have conducted research to develop a method for estimating crop water use that does not suffer from the limitations of the standard crop coefficient approach. The result is the "spectral crop coefficient" $\left(\mathrm{K}_{\mathrm{sp}}\right)$ approach [10]. Characteristics of the spectral crop coefficient are as follows: 1$)$ it is specific to individual fields (i.e., it does not represent "standard conditions" but rather the actual conditions occurring in a field); 2) it represents a physical quantity that can be measured in a field; and 3) it can be used to estimate the actual amount of water taken up and used by the growing crop (i.e., crop water use rather than ET). In this article, we will provide an overview of the $\mathrm{K}_{\mathrm{sp}}$ approach and present results from recent studies demonstrating its effectiveness in estimating crop water use under a variety of conditions.

\section{Materials and Methods}

\subsection{Spectral Crop Coefficient Approach}

Crop water use (CWU) can be defined as the water from irrigation, precipitation, and/or soil moisture reserves actually used by the growing crop. It is the water taken up by the plant roots and either used in photosynthesis (PS) or lost through transpiration (TR). So,

$$
\mathrm{CWU}=\mathrm{PS}+\mathrm{TR}
$$

In general, TR is much greater than PS, so

$$
\mathrm{CWU} \approx \mathrm{TR}
$$

CWU is not the same as ET, since ET includes soil evaporation.

In the spectral crop coefficient approach, daily CWU can be estimated using the following relationship,

$$
\mathrm{CWU}=\mathrm{K}_{\mathrm{sp}} \cdot \mathrm{PET}_{\mathrm{fc}} \cdot \mathrm{F}_{\text {stress }}
$$


where $\mathrm{PET}_{\mathrm{fc}}$ is the PET of a well-watered (non-stressed) crop with complete ground cover, and $\mathrm{F}_{\text {stress }}$ is a stress factor with a value ranging from 1 (no water stress) to 0 (fully stressed, non-transpiring plants) [10]. $K_{s p}$ is numerically equivalent to the ground cover (GC) of the crop, so it will have a value ranging from 1 (complete ground cover) to 0 (bare soil). Under non-stress conditions $\left(\mathrm{F}_{\text {stress }}=1\right)$, Equation (2) essentially states that CWU for a field is equal to the PET of the crop calculated as if it had $100 \%$ GC, multiplied by the fraction of GC actually present in the field. $\mathrm{F}_{\text {stress }}$ is introduced into the equation to reduce $\mathrm{CWU}$ under conditions where stomatal closure significantly reduces transpiration. Previous studies have suggested that, for crops that are acclimated to their field environment, the value of $\mathrm{F}_{\text {stress }}$ should be approximately 1 [10].

$\mathrm{PET}_{\mathrm{fc}}$ in $\mathrm{kg} \cdot \mathrm{m}^{-2} \cdot \mathrm{s}^{-1}$ is calculated using a form of the Penman-Monteith Equation,

$$
\operatorname{PET}_{\mathrm{fc}}=\left(\frac{1}{\lambda}\right) \frac{\Delta R_{n, f c}+\rho_{a} c_{p}\left(e_{s}-e_{a}\right) / r_{a, f c}}{\Delta+\gamma\left(1+r_{c p} / r_{a, f c}\right)}
$$

in which $R_{n, f c}$ is the net radiation in $\mathrm{MJ} \cdot \mathrm{m}^{-2} \cdot \mathrm{s}^{-1},\left(e_{s}-e_{a}\right)$ is the vapor pressure deficit of the air in $\mathrm{kPa}, \rho_{a}$ is the air density in $\mathrm{kg} \cdot \mathrm{m}^{-3}, c_{p}$ is the specific heat of air at constant pressure in $\mathrm{MJ} \cdot \mathrm{kg}^{-1} \cdot{ }^{\circ} \mathrm{C}^{-1}, \Delta$ is the slope of the saturation vapor pressure curve in $\mathrm{kPa} \cdot{ }^{\circ} \mathrm{C}^{-1}, \gamma$ is the psychrometric constant in $\mathrm{kPa} \cdot{ }^{\circ} \mathrm{C}^{-1}, \lambda$ is the latent heat of vaporization in $\mathrm{MJ} \cdot \mathrm{kg}^{-1}$, and $r_{c p}$ and $r_{a, f c}$ are the canopy and aerodynamic resistances, respectively, in $\mathrm{s} \cdot \mathrm{m}^{-1}$ [10]. In this expression, the values of $R_{n, f c}$ and $r_{a, f c}$ are representative of a crop with complete ground cover, and $r_{c p}$ represents the canopy resistance of a well-watered, unstressed crop. Soil heat flux has been omitted from this expression since it should be small under full canopy conditions. The weather observations required to evaluate Equation (4) are the same as those needed to calculate $\mathrm{ET}_{0}$ in the standard crop coefficient approach.

Since $\mathrm{K}_{\mathrm{sp}}$ is equivalent to crop GC, it can be measured for a field. For programs involving many fields within an agricultural region, measuring GC using standard photographic or light-interception techniques may be timeconsuming and labor-intensive. In these cases, GC can be estimated with reasonable accuracy using multispectral imagery from satellite or airborne remote sensing systems [11] [12]. Values of GC on days between remote sensing acquisitions can be estimated through interpolation. Thus, the spectral crop coefficient approach is wellsuited for application on a regional scale using operational sources of remote sensing imagery and weather data from existing observing networks.

\subsection{Study Sites}

Performance of the $K_{s p}$ approach under different environmental conditions was demonstrated using data from three commercial fields in the Southern High Plains of Texas. The three fields used in this study (hereafter referred to as Field 1, Field 2, and Field 3) were part of the Texas Alliance for Water Conservation (TAWC) Demonstration Project, a large project conducted in this region to promote conservation of regional water resources. All three fields were planted to cotton (Gossypium hirsutum L.) and managed in a manner consistent with current farming practices in the region. All three fields were rectangular in shape. The study was conducted in Fields 1 and 3 in 2008 and in Field 2 in 2010. Field 1 contained 14.5 ha and was located approximately 3.25

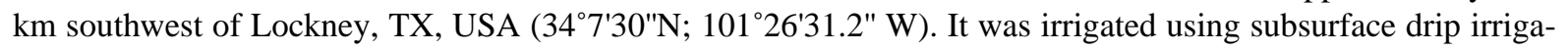
tion and had crop rows oriented north-south. Field 1 received approximately $600 \mathrm{~mm}$ of irrigation during the growing season, and the irrigation was terminated on 8 September 2008 (Day 252). Field 2 was located approximately $1 \mathrm{~km}$ south of Lockney and contained 18.0 ha. It was irrigated using subsurface drip irrigation and had crop rows oriented east-west. Field 2 received approximately $100 \mathrm{~mm}$ of irrigation during the growing season, and the irrigation was terminated on 28 August 2010 (Day 240). Field 3 was located approximately $3.25 \mathrm{~km}$ north of Lockney and contained 20.6 ha. It had crop rows oriented east-west and was not irrigated ("dryland"). Field 1 was planted on 5 May 2008 (Day 126), Field 2 on 15 May 2010 (Day 135), and Field 3 on 21 May 2008 (Day 142). The soil in all three fields is a Pullman clay loam (fine, mixed, thermic, Torrertic Paleustoll) with 0\% - $1 \%$ slope [13]. The climate of the study region is semi-arid with an average annual precipitation of approximately $460 \mathrm{~mm}$ [14].

\subsection{Eddy Covariance Data}

Daily observed values of CWU for comparison with corresponding estimates calculated using the Ksp approach were obtained from surface energy balance measurements made using an eddy covariance (EC) system operated 
at each field. In 2008, the EC system was mounted on a trailer that could be placed at the edge of the field (Field 1 and Field 3) to make measurements when the wind was blowing across the field in the direction of the trailer. The trailer had an erectable mast holding the sonic anemometer, infrared gas analyzer, and temperature/humidity probe. These sensors were mounted on the mast according to recommendations provided by the manufacturer [15]. These sensors were maintained at a height of $2 \mathrm{~m}$ above the height of the plant canopy. Sensors used to measure soil heat flux were buried in the field according to recommendations provided by the manufacturer [15]. A net radiometer was mounted on a tripod in the field approximately $2 \mathrm{~m}$ above the plant canopy. Data from all sensors were measured and recorded at a 20-Hz sampling rate using a CR3000 data logger (Campbell Scientific, Logan, UT). The raw high frequency data from the EC system were processed using a set of procedures described by Rajan et al. [10]. Thirty-minute average values of sensible heat flux, latent heat flux (ET), soil heat flux, and net radiation were calculated from the processed data.

The trailer supporting the EC system was situated along the north edge of the field it was measuring, approximately halfway between the east and west borders of the field. Data from the EC system were excluded from analysis if the wind direction was less than $110^{\circ}$ or more than $250^{\circ}$ (measured clockwise from north) in order to exclude situations where the fetch was not dominated by the field environment. In 2010, the EC system was mounted on a tripod located near the center of the field (Field 2). In this case, data did not need to be excluded based on wind direction.

EC data were used in this study only for those days when the soil surface in the field was observed to be dry. This was intended to minimize the contribution of soil evaporation to the overall latent heat flux measured by the EC system so that the measured ET approximated CWU as previously defined. Use of subsurface drip irrigation in Fields 1 and 2 resulted in the soil surface being dry except immediately following rainfall events. Since Field 3 was not irrigated, its soil surface was also dry except immediately following rainfall events.

In 2008, the EC system was stationed at Field 1 from 7 August (Day 220) through 4 October (Day 278), resulting in 14 days for which the wind direction and soil dryness criteria were met. During that year, a second EC system was stationed at Field 3 from 31 August (Day 244) through 3 October (Day 277), resulting in 8 days for which the wind direction and soil dryness criteria were met. In 2010, the EC system was stationed at Field 2 from 20 August (Day 232) through 21 September (Day 264), resulting in 32 days for which the soil dryness criterion was met. As these numbers suggest, placing the EC system in the middle of the field in 2010 resulted in significantly fewer days being excluded from analysis.

Energy balance closure was examined by summing the corresponding 30-minute average values of sensible heat flux, latent heat flux, soil heat flux, and net radiation. The resulting sum was usually less than zero, indicating that all the energy in the system was not accounted for by the EC measurements. This situation is common for EC measurements of agricultural and natural ecosystems [16]-[18]. In this study, it was assumed that the deficit in energy preventing closure resulted from underestimating the sensible and latent heat flux components. In these situations, the sensible and latent heat fluxes were adjusted by partitioning the residual in the energy balance between these two components according to the measured Bowen Ratio [19].

Daily CWU was obtained by summing the 30-minute average values of latent heat flux measured over the course of a day, divided by the latent heat of vaporization. Values of latent heat flux measured during the night were near zero and were excluded from the daily calculation.

\subsection{Satellite Data}

Satellite data for estimating crop GC $\left(=\mathrm{K}_{\mathrm{sp}}\right)$ were obtained from Landsat imagery. In 2008, Landsat-5 Thematic Mapper (TM) imagery containing the study site was acquired on 5 dates spanning the period when EC systems were stationed at Fields 1 and 3: 6 August (Day 219), 22 August (Day 235), 7 September (Day 251), 23 September (Day 267), and 9 October (Day 283). These acquisitions were supplemented by Landsat-7 Enhanced Thematic Mapper (ETM+) imagery acquired on 2 additional dates: 15 September (Day 259) and 1 October (Day 275). In 2010, Landsat-5 TM imagery containing the study site was acquired on 3 dates spanning the period when the EC system was stationed at Field 2:12 August (Day 224), 28 August (Day 240), and 29 September (Day 272). These acquisitions were supplemented by Landsat-7 ETM+ imagery acquired on one additional date: 5 September (Day 252).

Each image, located according to the Landsat World Reference System (WRS-2) along Path 30 at Row 36, was obtained from the U.S. Geological Survey (USGS) EarthExplorer website [20]. Pixel size in the imagery was specified as $30 \mathrm{~m}$, and Systematic Correction (L1G) was applied by USGS to the image data. In Systematic 
Correction, the image is rotated, aligned, and georeferenced to a user-defined map projection (WGS84), and is radiometrically corrected based on characteristics of the sensor [21].

Data extracted from the Landsat imagery were used to estimate crop GC for the study fields on each of the image acquisition dates using the procedure described by Maas and Rajan [11]. Image data analysis was carried out using ENVI image processing software (ITT, Boulder, CO). A scatterplot of each image (excluding portions containing clouds, cloud shadows, and water bodies) was constructed by plotting pixel digital count (DC) values in Band 4 (NIR spectral band) versus corresponding DC values in Band 3 (red spectral band). The bare soil line and the point corresponding to $100 \%$ GC was then identified by visual inspection of each scatterplot, allowing calculation of the value of the Perpendicular Vegetation Index (PVI) for 100\% GC for each image. The boundaries of the study fields were delineated in each Landsat image and average DC values in the red and NIR spectral bands were calculated for the pixels within the boundaries. These average values were used along with the appropriate equation of the bare soil line to calculate the value of PVI corresponding to each field. GC for each field on each image acquisition date was then calculated by dividing the PVI value corresponding to the field by the appropriate value of PVI corresponding to $100 \%$ GC. For each field, values of crop GC for days between satellite image acquisition dates were determined using linear interpolation.

\subsection{Weather Data and PET}

Since our intent was to demonstrate the application of the $\mathrm{K}_{\mathrm{sp}}$ approach under operational conditions, we chose to use commonly available weather observations to evaluate $\mathrm{PET}_{\mathrm{fc}}$ in Equation 3 rather than the detailed environmental measurements available from the EC systems stationed at the study fields. Daily weather data for the study period were obtained from the West Texas Mesonet (WTM), an operational network of observing stations scattered across the region including the study site [22]. Specifically, data were obtained from the WTM station at Plainview, Texas, located approximately $30 \mathrm{~km}$ to the west of the study site. Data included average daily air temperature $\left(T_{a}\right)$, average daily dew point temperature $\left(T_{d}\right)$, average daily wind speed $(u)$, and total daily solar irradiance $\left(Q_{s}\right)$. Values of $T_{a}, T_{d}$, and $u$ were measured at $2 \mathrm{~m}$ above the surface. Values of $T_{a}$ and $T_{d}$ were used to evaluate the vapor pressure deficit in Equation (4). Values of $u$ were used to evaluate the aerodynamic resistance in Equation 4 using the following equation,

$$
r_{a, f c}=\frac{\left[\ln \left(\frac{z-d}{z_{0}}\right)\right]^{2}}{k^{2} u}
$$

where $z$ is the measurement height, $d$ the zero-plane displacement, $z_{0}$ the surface roughness, and $k$ the Von Karman constant (0.41) [23]. In evaluating Equation 5, $z-d$ was assumed to be $2 \mathrm{~m}$. The value of $z_{0}$ for a cotton canopy with full cover was assumed to be $4 \mathrm{~cm}$ based on the results of previous studies [10]. Canopy resistance in Equation 4 was assumed to be $50 \mathrm{~s} / \mathrm{m}$, a value considered appropriate for non-stressed crop canopies with complete ground cover [24]. Net radiation in Equation 4 was evaluated from $Q_{s}$ and $T_{a}$ using procedures described by Allen et al. [2]. In calculating $R_{n, f c}$, the albedo of the surface was assumed to be 0.23 , which is appropriate for vegetation with $100 \%$ GC [2].

\subsection{Statistical Analysis}

Estimates of CWU were calculated using Equation (3) for days with EC measurements. In these calculations, the value of $\mathrm{F}_{\text {stress }}$ was set equal to 1 based on the assumption that the crop was acclimated to its environment. A paired $t$-test was used to determine if the average of the estimated CWU values was significantly different from the average of the observed values of CWU from the EC measurements [25]. In this calculation, the values from all three fields were combined to increase the sample size.

Estimated values of CWU were plotted versus corresponding observed values of CWU from the EC measurements. The distribution of points was fit using simple linear regression analysis. Data from all three fields were combined in this analysis to maximize the range of CWU values present in the data set and thereby make the regression more robust. Student's $t$ tests were used to determine if the slope of the regression was significantly different from 1 , and if the intercept of the regression was significantly different from zero [25]. Were that not the case, then one could conclude that the regression was not significantly different from the 1:1 line, and that the $\mathrm{K}_{\mathrm{sp}}$ approach did a reasonably good job of estimating CWU for the study. 
As a test of whether the assumption that $\mathrm{F}_{\text {stress }}=1$ was valid, Equation 3 was re-arranged and the value of $\mathrm{F}_{\text {stress }}$ was calculated as follows,

$$
\mathrm{F}_{\text {stress }}=\mathrm{CWU}_{\mathrm{obs}} /\left(\mathrm{K}_{\mathrm{sp}} \cdot \mathrm{PET}_{\mathrm{fc}}\right)
$$

in which $\mathrm{CWU}_{\mathrm{obs}}$ is the observed value of CWU from the EC measurements. A Student's $t$ test was used to determine if the average value of $\mathrm{F}_{\text {stress }}$ from this analysis was significantly different from 1 [25]. If this average value were not significantly different from 1 , then one could conclude that the crops in this study generally were acclimated to their surrounding environments. To further test this hypothesis, Student's $t$ tests were used to determine if the slope of the regression through these points was significantly different from zero, and if the intercept of the regression was significantly different from 1 [25]. Were that not the case, then one could conclude that the regression was not significantly different from a line with a constant $y$-value $\left(\mathrm{F}_{\text {stress }}\right)$ of 1 .

The difference was determined for each pair of estimated and observed CWU values and used to calculate the Average Absolute Error (AAE) according to the equation,

$$
\mathrm{AAE}=\frac{\sum_{i=1}^{n}\left|\mathrm{CWU}_{\text {est }}-\mathrm{CWU}_{\mathrm{obs}}\right|}{n}
$$

where $n$ is the number of observations. Data from all three study fields were combined for this analysis. AAE can be considered as a measure of the overall accuracy of the estimation approach.

\section{Results and Discussion}

Figure 1 shows GC values estimated from Landsat image data spanning the periods during which EC measurements were made at the three study fields. The differences in GC values among the three fields can largely be attributed to the type of irrigation each received. Field 1 received $600 \mathrm{~mm}$ of irrigation, an amount that would normally result in maximum growth of the crop (i.e., Field 1 was "fully irrigated"). GC for this field remained high during the period of EC measurements. The irrigation for this field was terminated on Day 252, and effects of this termination on crop GC occurred largely after the last Landsat overpass date (Day 259). Field 2 was "deficit irrigated" using only a modest amount of irrigation $(100 \mathrm{~mm})$ such that the growth of the crop was below the maximum level but still capable of producing acceptable yields. Deficit irrigation is a common practice among cotton farmers in this region. Compared to Field 1, the farmer began reducing irrigation earlier for Field

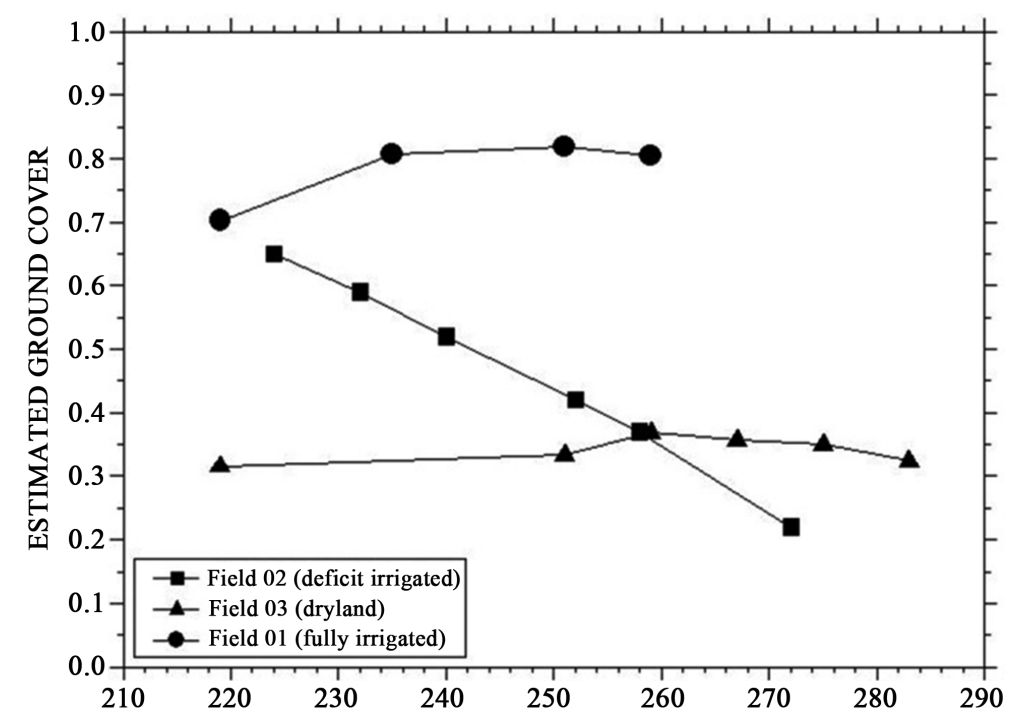

Figure 1. Ground cover values (solid symbols) estimated from Landsat image data spanning the periods during which eddy covariance measurements were made at the three study fields. Straight line segments connecting symbols were used to determine interpolated values of GC for days between Landsat overpass dates. 
2, and terminated irrigation altogether on an earlier date (Day 240). The result was a steady decline in crop GC for Field 2 over the period of EC measurements. Field 3 was a dryland field receiving no irrigation. Its GC remained relatively constant over the period of EC measurements, with a small increase in GC between Day 251 and Day 259 resulting from a rain event. These results show that both the magnitude and temporal dynamics of crop GC can vary markedly among fields in an agricultural region, emphasizing that methods for estimating CWU need to be field-specific.

An example of CWU estimates produced by the $K_{s p}$ method is presented in Figure 2. This figure shows daily CWU estimates for Field 2, along with their corresponding observed CWU values measured using EC. Both the observed and estimated CWU values exhibit a steady decrease over time as a result of the decrease in crop GC over the study period (see Figure 1). As shown in Figure 2, the least-squares linear regression fit to the observed values is very close to the corresponding least-squares linear regression fit to the estimated values over the study period. This suggests that the $\mathrm{K}_{\mathrm{sp}}$ method responded appropriately to the crop and environmental factors driving CWU in this field. The average absolute error (AAE) between estimated and observed CWU values was $0.69 \mathrm{~mm} /$ day. Results for Fields 1 and 3 are qualitatively similar to those for Field 2 .

Table 1 presents average daily estimated and observed CWU (mm/day) for each of the three fields in the study. The table also shows the average daily estimated and observed CWU for the combined data from the three fields. The paired $t$-test performed on the combined data resulted in $t=-0.0297$ with $56 \mathrm{df}$. This value was less than the corresponding critical value $\left(t_{\alpha=0.05,56 \mathrm{df}}=2.004\right)$, which suggests that there was no significant difference between the average estimated and observed values of CWU in this study.

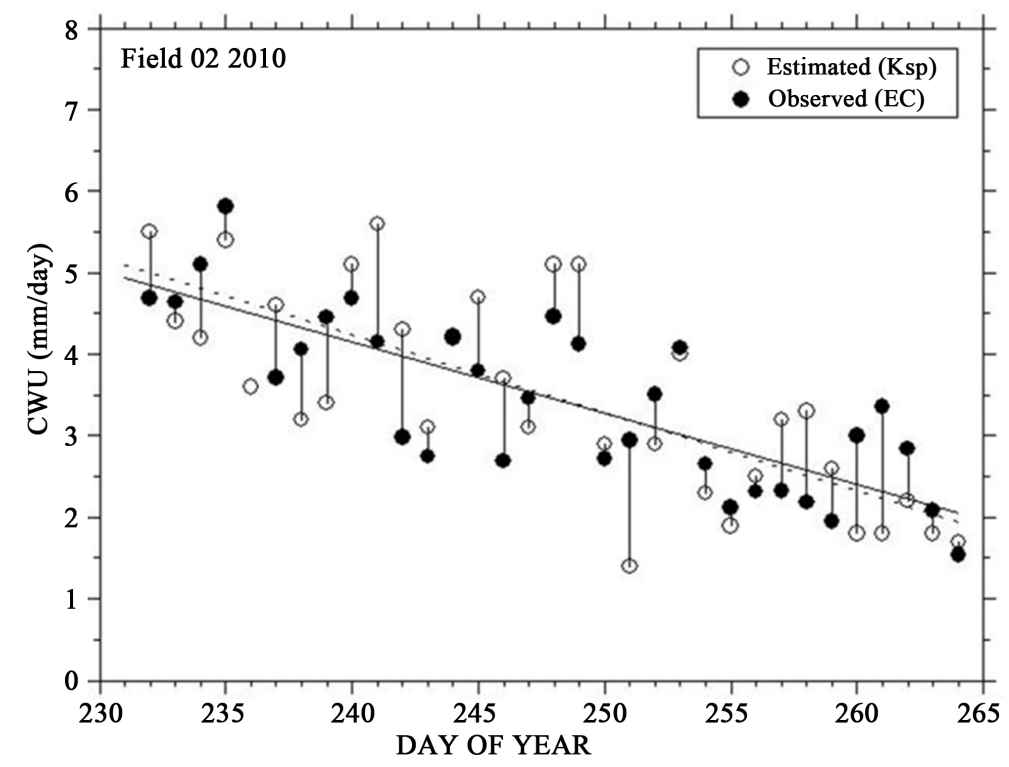

Figure 2. Estimated daily values of CWU (open circles) plotted along with their corresponding observed values of CWU (solid circles) for Field 2 in the study. Vertical lines connect the pairs of estimated and observed values. The solid line passing through the set of points is the least-squares fit to the observed values, while the dashed line is the least-squares fit to the estimated values.

Table 1. Average daily CWU (mm/day) for each of the three fields and for the combination of the data from the three fields.

\begin{tabular}{ccc} 
& detamitsE & devresbO \\
\hline dleiF 01 & 5.68 & 5.47 \\
Field 02 & 3.47 & 3.43 \\
dleiF 03 & 2.15 & 1.90 \\
All 3 Fields & 3.80 & 3.72 \\
\hline
\end{tabular}


Figure 3 shows observed values of CWU plotted versus their corresponding values of estimated CWU for the three fields in the study. The diagonal solid line in the figure represents the 1:1 line. Points in the figure tend to cluster along the 1:1 line over the range of CWU values. The dashed line represents the simple linear regression fit to the points in the figure. This regression line has a slope of 0.926 and a y-intercept of 0.278 , and explains approximately $80 \%$ of the total variance in the data. The $t$-test performed to determine if the regression slope was significantly different from 1 resulted in $t=-1.112$ with $54 \mathrm{df}$. This value was less than the corresponding critical value $\left(t_{\alpha=0.05,54 \mathrm{df}}=2.005\right)$, which suggests that there was no significant difference between the slope of the regression and 1 . The $t$-test performed to determine if the regression intercept was significantly different from zero resulted in $t=1.033$ with $54 \mathrm{df}$. This value was less than the corresponding critical value $\left(t_{\alpha=0.05,54 \mathrm{df}}=\right.$ 2.005), which suggests that there was no significant difference between the y-intercept of the regression and zero. Overall, these results suggest that there was no significant difference between the regression line and the 1:1 line in this study.

Figure 4 shows values of $\mathrm{F}_{\text {stress }}$ calculated using Equation (6) plotted versus their corresponding values of $\mathrm{CWU}_{\mathrm{obs}}$. There is considerable scatter in the points over the range of observed $\mathrm{CWU}$, but they tend to cluster around a value of 1 with an average value of 1.028 for the combined data set. The t-test performed to determine if this average value was significantly different from 1 resulted in $t=0.725$ with $56 \mathrm{df}$. This value was less than the corresponding critical value $\left(t_{\alpha=0.05,56 \mathrm{df}}=2.004\right)$, which suggests that there was no significant difference between the average value of $\mathrm{F}_{\text {stress }}$ and 1 in this study.

The dashed line in Figure 4 represents the simple linear regression fit to the points in the figure. This regression line has a slope of -0.0392 and a y-intercept of 1.174 . The $t$-test performed to determine if the regression slope was significantly different from 0 resulted in $t=-1.650$ with $54 \mathrm{df}$. This value was less than the corresponding critical value $\left(t_{\alpha=0.05,54 \mathrm{df}}=2.005\right)$, which suggests that there was no significant difference between the slope of the regression and zero. The $t$-test performed to determine if the regression intercept was significantly different from 1 resulted in $t=1.806$ with $54 \mathrm{df}$. This value was less than the corresponding critical value $\left(t_{\alpha=0.05,54 \mathrm{df}}=2.005\right)$, which suggests that there was no significant difference between the y-intercept of the regression and 1 . Overall, these results suggest that there was no significant difference between the regression line

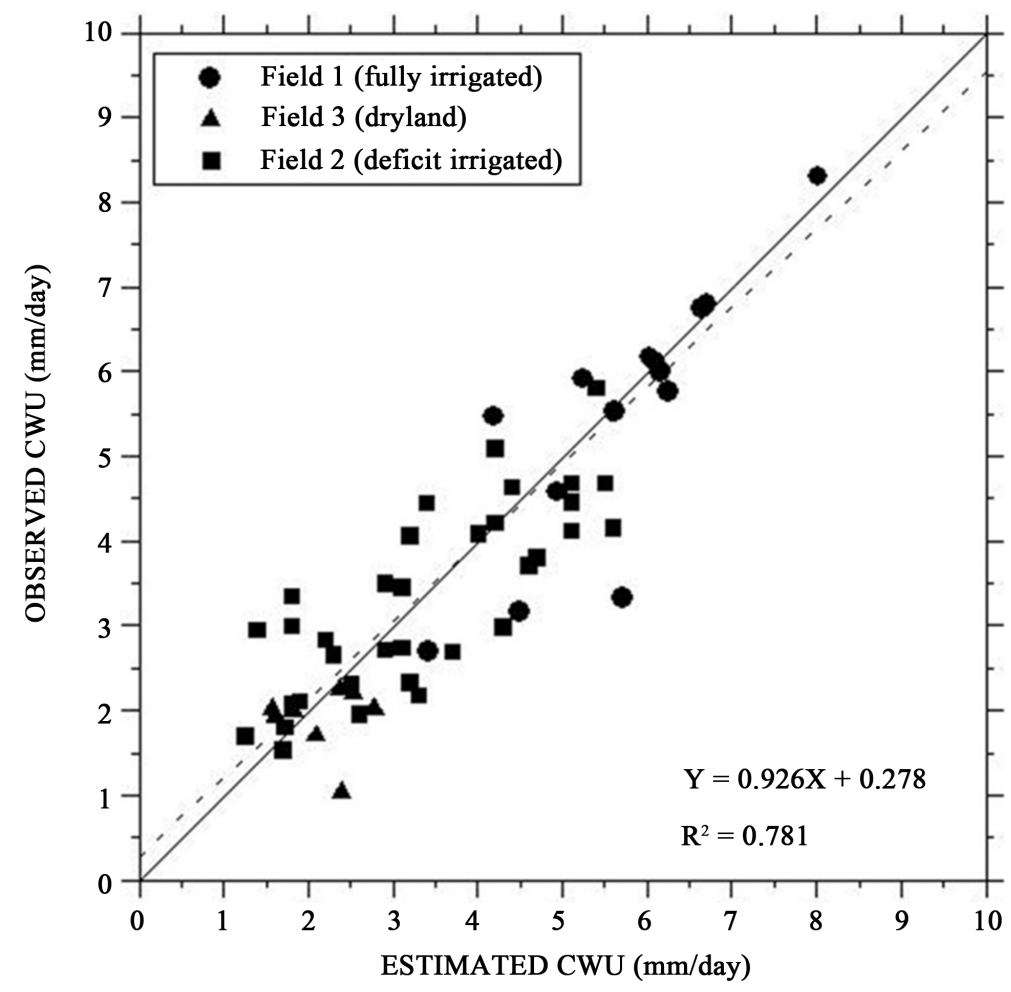

Figure 3. Estimated versus observed CWU for the three cotton fields in the study. The solid diagonal line is the 1:1 line, while the dashed line is the leastsquares regression fit to the data. 


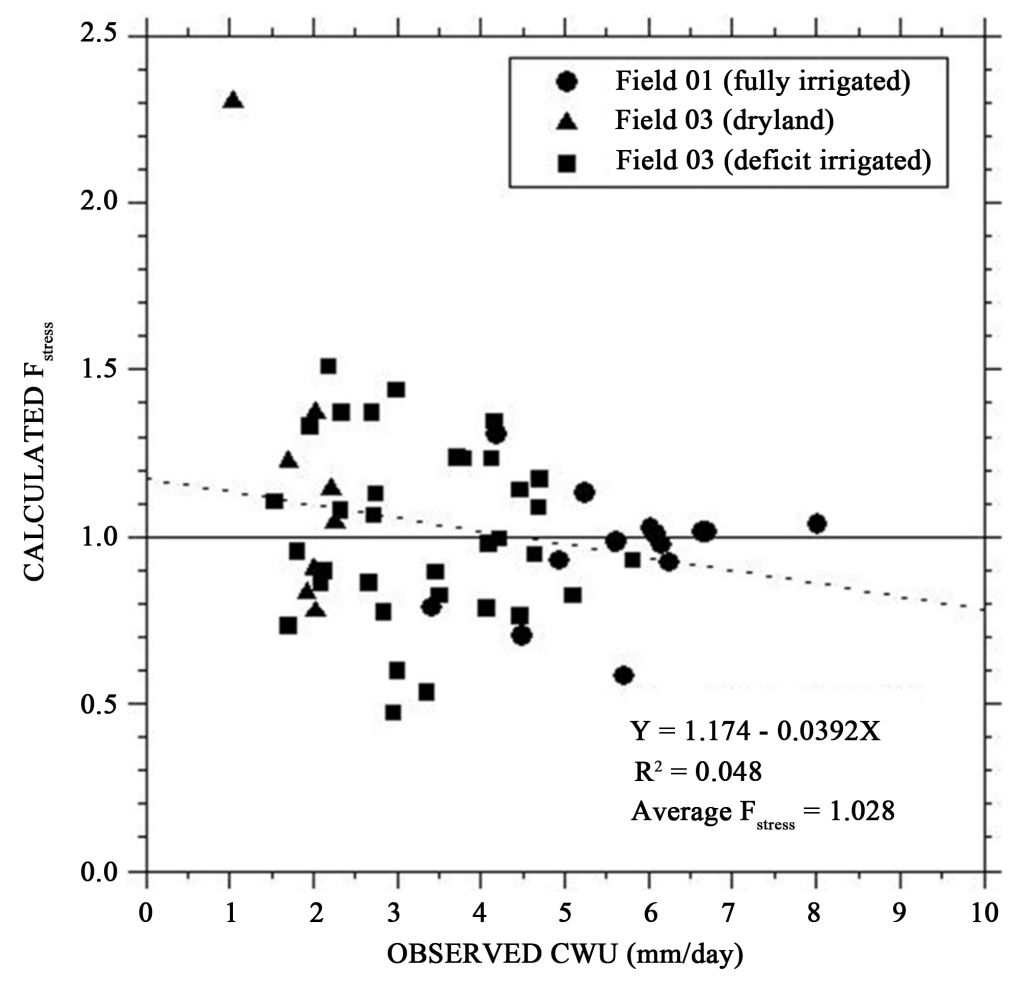

Figure 4. Calculated values of the stress factor $F_{\text {stress }}$ plotted versus their corresponding values of observed CWU for the three cotton fields in the study. The solid horizontal line represents a value of $F_{\text {stress }}$ equal to 1 . The dashed line represents the least-squares regression fit to the data.

and a line with a constant $y$-value $\left(F_{\text {stress }}\right)$ of 1 . Note that, if the extreme point in Figure 4 ( $\left.x=1.042, y=2.302\right)$ is removed from the analysis, the results (in terms of the conclusions drawn from the statistical tests on the slope and $y$-intercept of the regression and the average $\mathrm{F}_{\text {stress }}$ value) remain the same.

There was considerable scatter among the individual values plotted in Figure 3 and Figure 4. Since the data used to determine estimated and observed values of CWU came from a number of diverse sources (satellite imagery, weather network observations, and in-field EC measurements), the opportunity existed for random errors (which might compound or cancel) to be introduced in multiple stages of the calculations. Still, the statistical analysis of the results suggests that the $\mathrm{K}_{\mathrm{sp}}$ approach performed reasonably well in estimating daily CWU for the three fields. The $\mathrm{K}_{\mathrm{sp}}$ approach produced results that were field-specific, and it appeared to perform reasonably well for all three types of irrigation (fully irrigated, deficit irrigated, and not irrigated) used in this study. The AAE for CWU estimates for the combined data from the three fields was $0.62 \mathrm{~mm} /$ day suggesting that, on average, estimates of CWU produced by the approach should have sub-mm accuracy.

The results presented in Figure 3 and Figure 4 suggest that differences in CWU among the types of irrigation were predominantly the result of differences in crop GC rather than differences in stress induced by stomatal closure. During the study period, average values of GC deduced from the satellite data for the crops in Fields 1 (fully irrigated), Field 2 (deficit irrigated), and Field 3 (dryland) were 0.82, 0.48 and 0.35, respectively. Thus, the crops in this study appeared to be acclimated to their surrounding environments and were controlling their seasonal transpirational losses through manipulation of their leaf area in order to maintain their stomata in an open and functional condition. A physiological mechanism for this behavior has been described [26]. As plants deplete the water in the soil profile, they begin to experience reduced leaf growth and increased leaf senescence at a value of available soil water of around $50 \%$ of field capacity. For these plants, stomatal closure and reduced leaf transpiration is delayed until levels of available soil water fall to around $30 \%$ of field capacity. Thus, these plants have the opportunity to conserve soil water by reducing the surface area of the leaf canopy while maintaining photosynthesis in the remaining leaves.

Since leaves grow and senesce at a relatively slow rate as compared to stomatal function, this mechanism for 
acclimatization would be most effective when changes in environmental conditions (such as soil water) are gradual, as generally occurs in field environments. Abrupt changes, as when the irrigation to well-watered crops is terminated, can result in periods of stomatal closure while the plants adjust their canopy size through accelerated leaf senescence [10].

The $K_{\text {sp }}$ approach is well-suited for applications such as irrigation scheduling. Its use of operational weather observations (the same as used in the standard crop coefficient approach) and readily available satellite image data make it easy to apply on a regional scale, while the evaluation of the crop coefficient from actual satellitederived field observations allows its CWU estimates to be field-specific. Use of field-specific CWU estimates should help minimize over-irrigation of fields and thus contribute to water conservation.

\section{Conclusion}

Results of this study suggest that the spectral crop coefficient approach is effective in estimating the CWU of agricultural fields under a variety of irrigation conditions ranging from fully irrigated to dryland. In this approach, CWU can be evaluated from standard weather observations from operational weather observing networks and readily available medium-resolution multispectral satellite imagery. The use of satellite data in the method allows the estimates of CWU to be specific to individual fields, as opposed to the standard crop coefficient approach in which estimates of crop ET assume "standard conditions" that are invariant from field to field. Under field conditions where the crop is acclimated to its environment, water use is controlled more by crop ground cover than by stomatal closure. On average, CWU estimates produced by the $\mathrm{K}_{\mathrm{sp}}$ approach might be expected to have sub-mm accuracy. The $\mathrm{K}_{\mathrm{sp}}$ approach is well-suited for operational applications such as irrigation scheduling, where its use could contribute to water conservation by minimizing over-irrigation.

\section{Acknowledgements}

The authors wish to thank the Texas Alliance for Water Conservation (TAWC) Demonstration Project, funded through the Texas Water Development Board, for the resources to conduct this study.

\section{References}

[1] Burman, R.D. (2003) Evapotranspiration Formulas. In: Stewart, B.A. and Howell, T.A., Eds., Encyclopedia of Water Science, Marcel Dekker, New York, 253-257.

[2] Allen, R.G., Pereira, L.S., Raes, D. and Smith, M. (1998) Crop Evaporation: Guidelines for Computing Crop Water Requirements. Irrigation and Drainage Paper 56, Food and Agriculture Organization of the United Nations, Rome.

[3] Heilman, J.L., W.E. Heilman, and D.G. Moore (1982) Evaluating the Crop Coefficient Using Spectral Reflectance. Agronomy Journal, 74, 967-971. http://dx.doi.org/10.2134/agronj1982.00021962007400060010x

[4] Bausch, W.C. and Neale, C.M.U. (1987) Crop Coefficients Derived from Reflected Canopy Radiation: A Concept. Transactions of ASAE, 30, 703-709. http://dx.doi.org/10.13031/2013.30463

[5] Bausch, W.C. and Neale, C.M.U. (1989) Spectral Inputs Improve Corn Crop Coefficients and Irrigation Scheduling. Transactions of ASAE, 32, 1901-1908. http://dx.doi.org/10.13031/2013.31241

[6] Neale, C.M.U., Bausch, W.C. and Heerman, D.F. (1989) Development of Reflectance Based Crop Coefficients for Corn. Transactions of ASAE, 28, 773-780.

[7] Bausch, W.C. (1995) Remote-sensing of Crop Coefficients for Improving the Irrigation Scheduling of Corn. Agricultural Water Management, 27, 55-68. http://dx.doi.org/10.1016/0378-3774(95)01125-3

[8] Hunsaker, D.J., Pinter Jr., P.J., Barnes, E.M. and Kimball, B.A. (2003) Estimating Cotton Evapotranspiration Crop Coefficients with a Multispectral Vegetation Index. Irrigation Science, 22, 95-104. http://dx.doi.org/10.1007/s00271-003-0074-6

[9] Hunsaker, D.J., Pinter Jr., P.J. and Kimball, B.A. (2005) Wheat Basal Crop Coefficients Determined by Normalized Difference Vegetation Index. Irrigation Science, 24, 1-14. http://dx.doi.org/10.1007/s00271-005-0001-0

[10] Rajan, N., Maas, S.J. and Kathilankal, J. (2010) Estimating Crop Water Use of Cotton in the Texas High Plains. Agronomy Journal, 102, 1641-1651. http://dx.doi.org/10.2134/agronj2010.0076

[11] Maas, S.J. and Rajan, N. (2008) Estimating Ground Cover of Field Crops Using Medium-Resolution Multispectral Satellite Imagery. Agronomy Journal, 100, 320-327. http://dx.doi.org/10.2134/agrojnl2007.0140

[12] Rajan, N. and Maas, S.J. (2009) Mapping Crop Ground Cover Using Airborne Multispectral Digital Imagery. Preci- 
sion Agriculture, 10, 304-318. http://dx.doi.org/10.1007/s11119-009-9116-2

[13] NRCS (1978) Soil Survey of Floyd County, Texas. Natural Resource Conservation Service, US Department of Agriculture, Washington DC.

[14] Larkin, T.J. and Bowmar, G.W. (1983) Climatic Atlas of Texas. Publication LP-192, Texas Department of Water Resources, Austin.

[15] Campbell Scientific (2006) Open-Path Eddy Covariance System Operator’s Manual (Revised 9/06). Campbell Scientific, Inc., Logan.

[16] Foken, T. (2008) The Energy Balance Closure Problem: An Overview. Ecological Applications, 18, 1351-1367. http://dx.doi.org/10.1890/06-0922.1

[17] Wilson, K., Goldstein, A., Falge, E., Aubinet, M., Baldocchi, D., Berbigier, P., Bernhofer, C., Ceulmans, R., Dolman, H., Field, C., Grelle, A., Ibrom, A., Law, B.E., Kowalsky, A., Meyers, T., Moncrieff, J., Monson, R., Oechel, W., Tenhunen, J., Valentini, R. and Verma, S. (2002) Energy Balance Closure at FLUXNET Sites. Agricultural and Forest Meteorology, 113, 223-243. http://dx.doi.org/10.1016/S0168-1923(02)00109-0

[18] Mauder, M., Liebenthal, C., Göckede, M., Leps, J., Beyrich, F. and Foken, T. (2006) Processing and Quality Control of Flux Data during LITFASS-2003. Boundary-Layer Meteorology, 121, 67-88. http://dx.doi.org/10.1007/s10546-006-9094-0

[19] Twine, T.E., Kustas, W.P., Norman, J.M., Cook, D.R., Houser, P.R., Meyers, T.P., Prueger, J.P., Starks, P.J. and Wesley, M.L. (2000) Correcting Eddy-Covariance Flux Underestimates over a Grassland. Agricultural and Forest Meteorology, 103, 279-300. http://dx.doi.org/10.1016/S0168-1923(00)00123-4

[20] http://edcsns17.cr.usgs.gov/EarthExplorer/

[21] Chander, G. and Markham, B. (2003) Revised Landsat-5 TM Radiometric Calibration Procedures and Postcalibration Dynamic Ranges. IEEE Transactions on Geoscience and Remote Sensing, 41, 2674-2677. http://dx.doi.org/10.1109/TGRS.2003.818464

[22] http://www.mesonet.ttu.edu/

[23] Monteith, J.L. and Unsworth, M. (1990) Principles of Environmental Physics. Edward Asner Publishers, London.

[24] Allen, R.G., Pruitt, W.O., Wright, J.L., Howell, T.A., Ventura, F., Snyder, R., Itenfisu, D., Steduto, P., Berengena, J., Yrisarry, J.B., Smith, M., Pereira, L.B., Raes, D., Perrier, A., Alves, I., Walter, I. and Elliott, R. (2006) A Recommendation on Standardized Surface Resistance for Hourly Calculation of Reference ET $_{0}$ by the FAO56 Penman-Monteith Method. Agricultural Water Management, 81, 1-22. http://dx.doi.org/10.1016/j.agwat.2005.03.007

[25] Ostle, B. and Mensing, R.W. (1982) Statistics in Research. Iowa State University Press, Ames.

[26] Rosenthal, W.D., Arkin, G.F., Shouse, P.J. and Jordan, W.R. (1987) Water Deficit Effects on Transpiration and Leaf Growth. Agronomy Journal, 79, 1019-1026. http://dx.doi.org/10.2134/agronj1987.00021962007900060014x 
Scientific Research Publishing (SCIRP) is one of the largest Open Access journal publishers. It is currently publishing more than 200 open access, online, peer-reviewed journals covering a wide range of academic disciplines. SCIRP serves the worldwide academic communities and contributes to the progress and application of science with its publication.

Other selected journals from SCIRP are listed as below. Submit your manuscript to us via either submit@scirp.org or Online Submission Portal.
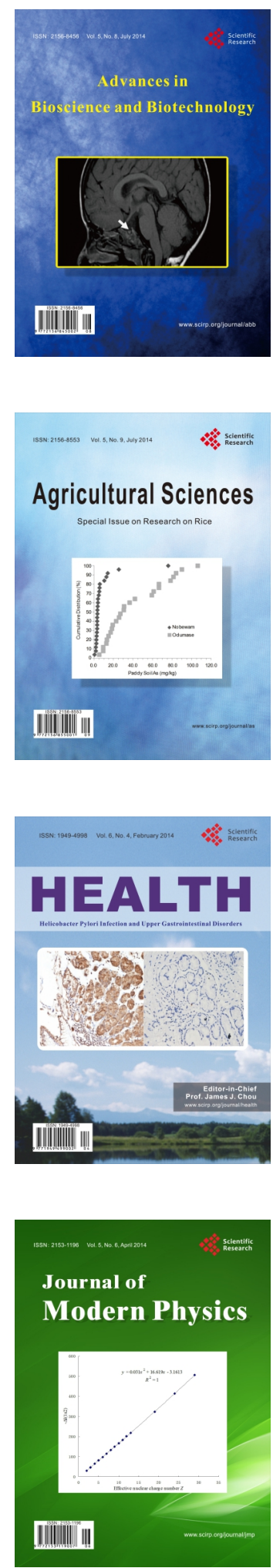
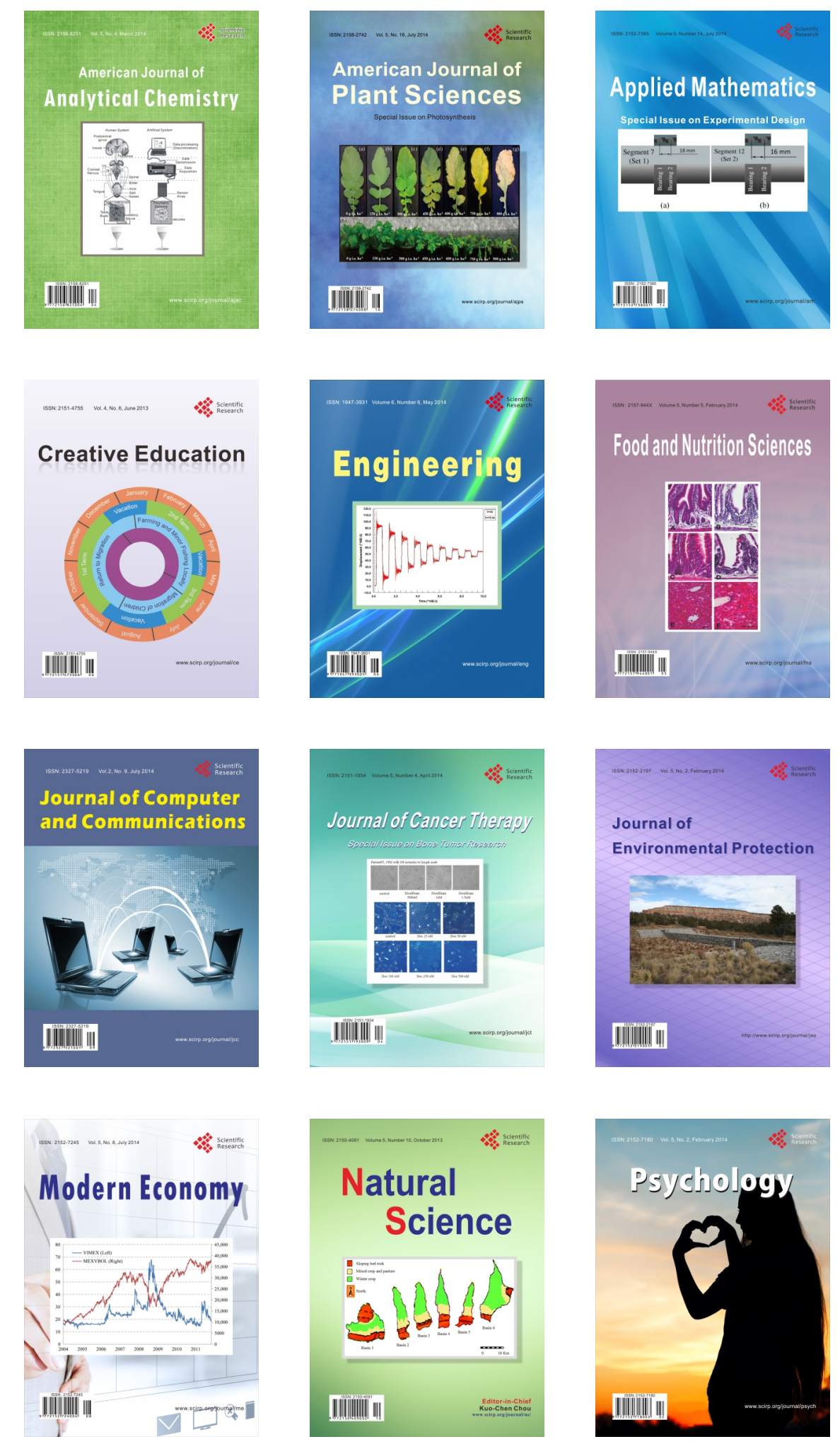